\title{
Status and Prospect of Remanufacturing Technology for Tubing and Sucker Rods
}

\begin{abstract}
As the main consumables, huge amount of tubing and sucker rods are abandoned annually. The current remediation technology could only enable part of abandoned tubing and sucker rod to be reused in a degraded way, leading to a big resource waste. The production, use and remediation methods of tubing and sucker rod are analyzed here. Remanufacturing technology of abandoned tubing based on self-propagating high temperature synthesis (SHS) is proposed. Economic, environmental and social benefits of large scale application of this technology are evaluated. And then various factors that restrict the popularization of remanufacturing technology in the petroleum industry are studied and suggestions are given in the end. The results indicate that unlike conventional remediation methods, remanufacturing technology can extend the service life of abandoned tubing to reach or even exceed that of a new one. Meanwhile it can also reduce the cost effectively, and achieve significant economic and social benefits. We should expand remanufacturing technology areas in the petroleum industry and achieve stable, healthy development in the low oil price situation. The scientific standards for remanufactured products should be enacted, and new management mode of the remanufactured products should be developed.
\end{abstract}

Keywords: remanufacturing, SHS, tubing, sucker rods

\section{Introduction}

With the deepening development of special reservoirs as heavy oil, low permeability, etc., corrosion and sand production of oil and water wells are becoming increasingly serious. In the hostile environment, tubing and sucker rod are prone to failure, resulting in huge amounts of

Manuscript received January 4, 2016; accepted July 10, 2016

He Liu ( $₫)$, Tao Li, Wei-ye Han, Qiang Chen, Shou-zhi Huang, Er-yang Ming, Qiang Sun

Research Institute of Petroleum Exploration and Development, China National Petroleum Corporation, Beijing 100083, China

Email: liuhe@petrochina.com.cn abandoned tubing. Existing remediation technology applies only to part of the light damaged abandoned tubing and the repaired tubing are used degradedly, resulting in tremendous waste of resources.

Remanufacturing technology is the industry of remedying and reforming abandoned products by high-tech. Based on damaged or abandoned products and parts, the quality and performance of remanufactured products can meet or exceed that of new products with a series of advanced manufacturing technology. As the typical form of green manufacturing and recycle economy, remanufacturing technology is an inevitable choice for the cycle development of industries (Field \& Sroufe, 2007; Hu, Wang, \& Xu, 2000; Xu, 2010).

Utilizing advanced remanufacturing technology on abandoned tubing and sucker rod, it can greatly prolong the service life of tubing and sucker rod, extend pump inspection period, reduce operation costs, reduce comprehensive cost significantly, realize good economic, social and environmental value. And it has broad application prospects.

\section{Using status and conventional remedia- tion technologies of tubing and sucker rods}

Annual production capacity of tubing and sucker rod in China ranks first in the world, and annual usage demand is tremendous. According to statistics, annual production capacity of oil well pipes in China, including tubing, casing, drill pipe, etc., has reached 10 million tons which is more than two-thirds of world annual production capacity. Annual usage of oil well pipes in domestic oil fields is about 3 million tons. Annual production capacity of sucker rod is around 200 million meters which ranks first in the world. And annual usage of sucker rod in domestic oil fields is around 120 million meters.

Currently there are about 328,000 wells in 15 oil fields of CNPC, including oil wells, water wells and gas wells, and the length of oil well pipes is more than 440 million meters (more than 4 million tons). There are around 70,000 wells 
in 12 oil fields of Sinopec, and the length of oil well pipes is more than 220 million meters (more than 2 million tons). And there are over 117,000 wells in Shaanxi Yanchang Petroleum. Annual interior amount of abandoned tubing is about 700,000 tons, and that of abandoned sucker rod is over ten million meters. As an example of Jilin oilfield in 2015 , the number of in-service tubing was 174,200 tons, and the number of waste tubing was 12,600 tons accounting for $7.3 \%$ of the total amount. The number of in-service sucker rod was 69.31 million meters, and the number of waste sucker rod was 48.689 million meters accounting for $70.2 \%$ of the total amount. These caused serious economic losses and waste of resources for oil field.

Currently, waste tubing and sucker rod handling lacks of uniform industry standards. The oilfield enterprises enact the abandon determination standards in accordance with their respective conditions and damage degree of tubing and sucker rod. Sinopec has developed "repair tubing quality requirements," which provided tubing abandon conditions including the tube spiral bending, hole blocked, pipe wall corrosion cracking, etc. (Figure 1, Figure 2, and Figure 3). Daqing has developed the ideas that "waste is crimination standards for old tubing" and "waste is crimination standards for $20 \mathrm{CrMo}$ process-type sucker rod and $30 \mathrm{Mn} 2 \mathrm{SiV}$ materials-type sucker rods." The waste tubing evaluation criterion is shown as Table 1. The evaluation criterion of $20 \mathrm{CrMo}$ process-type sucker rod is shown as Table 2 .

According to the existing waste discrimination standards, repairable tubing could be repaired by sorting, cleaning, straightening, inspection, thread repairing, coupling replace, pressuring and other routine process (Figure 4). Repairable sucker rod could be repaired by sorting, cleaning, surface inspection, polishing, straightening, thread repairing, supersonic frequency quenching, secondary inspection polishing, shot blasting, pressuring and other routine process (Figure 5).

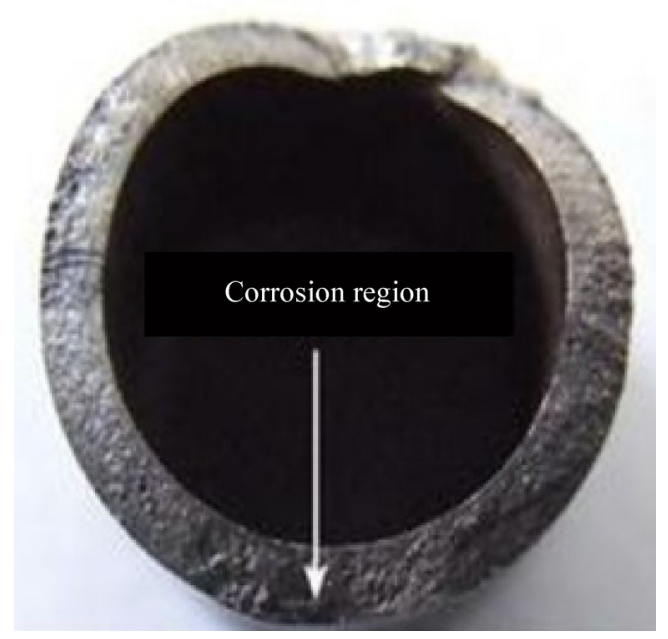

Figure 1. Corrosion.

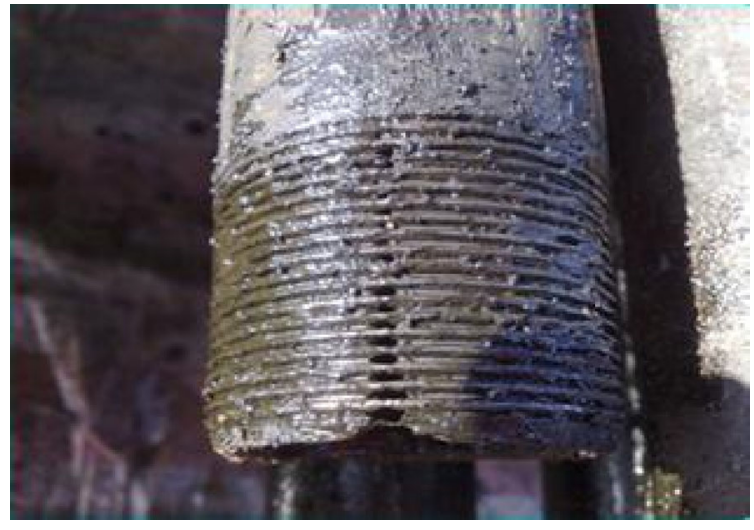

Figure 2. Screw thread damage.

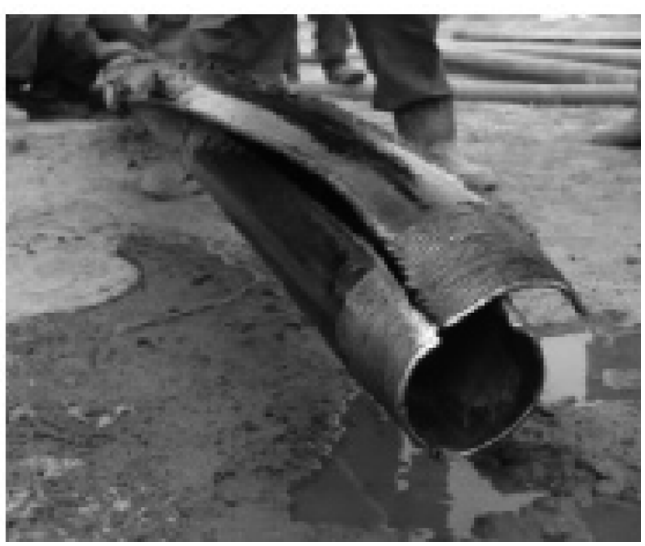

Figure 3. Tube broke.

Conventional remediation technologies have limit range of application. And the pipes would be used degradedly after repairing. The geometric defects caused by corrosion and abrasion have not been fixed. Products have risk of being abandoned during sorting, inspection, and pressuring. This can easily lead to a waste of resources, cannot meet the development of green recycling economy.

\section{Remanufacturing technology for tubing and sucker rods}

Remanufacturing is a series of technical measures or project activities of waste products repairing and transforming, which is guided by theory of product life-cycle, formulated with high quality, high efficiency, saving energy, raw materials, environmental protection as standard and implemented by advanced technology and industrial production. Remanufacturing technology in China, starting in 2000, is developed on the basis of maintenance engineering and surface engineering. It mainly utilizes dimension recovery methods and performance improvement methods to improve remanufacturing rate and reduce 
Table 1

Waste Tubing Evaluation Criterion

\begin{tabular}{|c|c|c|c|c|c|c|}
\hline \multirow{2}{*}{ No. } & \multirow{2}{*}{ Tube appearance } & \multicolumn{2}{|l|}{ Pipe body } & \multirow{2}{*}{ External thread } & \multirow{2}{*}{ Collar } & \multirow{2}{*}{ Evaluation } \\
\hline & & Pipe wall & $\overline{\text { Scale buildup }}$ & & & \\
\hline 1 & Oil contamination & Oil contamination & N/A & Galling & Corrosion & Esed tubing \\
\hline 2 & Slight corrosion & Slight abrasion $(<12.5 \%)$ & Powder & Galling & Corrosion & Primary crust tubing \\
\hline 3 & Severe scaling and corrosion & Abrasion $(25 \%)$ & Solid & Rupture & Corrosion & Secondary crust tubing \\
\hline 4 & Bending and blocking & Abrasion $(>25 \%)$ & Solid & Rupture & $\begin{array}{c}\text { Corrosion and } \\
\text { abrasion }\end{array}$ & Abandoned tubing \\
\hline
\end{tabular}

Table 2

Evaluation Criterion of 20CrMo Process-type Sucker Rod

\begin{tabular}{|c|c|c|c|c|c|}
\hline \multirow[b]{2}{*}{ Diameter of rod (mm) } & \multicolumn{2}{|c|}{ Qualified rod } & \multicolumn{2}{|c|}{ Degradation rod } & \multirow[b]{2}{*}{ Abandoned rod } \\
\hline & Operation la & ection period & \multicolumn{2}{|c|}{$\begin{array}{c}\text { Operation lasting a pump inspection period } \\
\text { under } 30 \mathrm{kN} \text { load }\end{array}$} & \\
\hline$\oint 16$ & \multirow{4}{*}{ crack $\leqslant$} & $0.21 \mathrm{~mm}$ & \multirow{4}{*}{$<$ crack $\leqslant$} & $0.35 \mathrm{~mm}$ & \multirow{4}{*}{$<$ crack } \\
\hline$\oint 19$ & & $0.33 \mathrm{~mm}$ & & $0.54 \mathrm{~mm}$ & \\
\hline$\oint 22$ & & $0.46 \mathrm{~mm}$ & & $0.74 \mathrm{~mm}$ & \\
\hline$\oint 25$ & & $0.62 \mathrm{~mm}$ & & $0.99 \mathrm{~mm}$ & \\
\hline
\end{tabular}

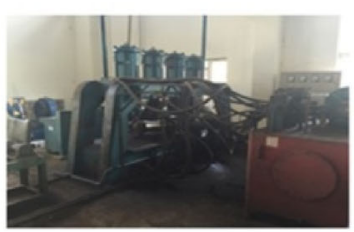

Straightening

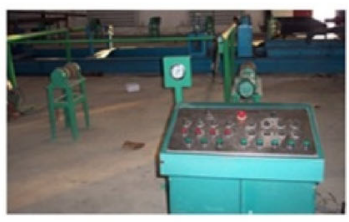

Pressure test

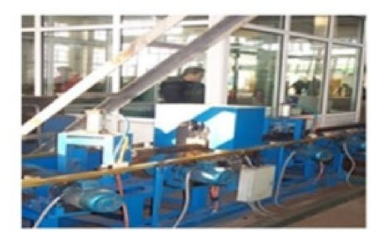

Flaw detection

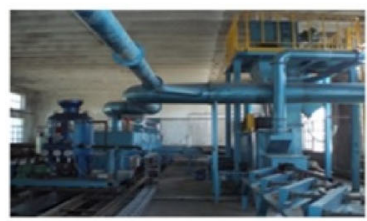

Derusting

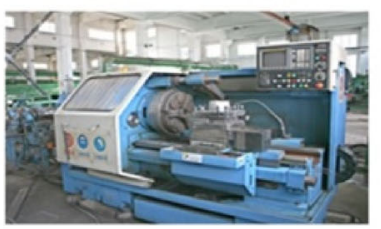

Cutting thread

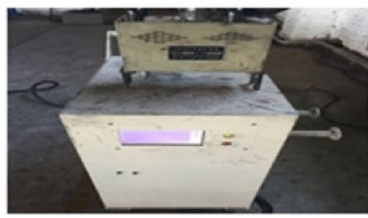

Marking

Figure 4. Repair technology of waste tubing.

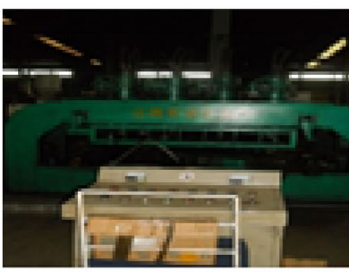

Straightening

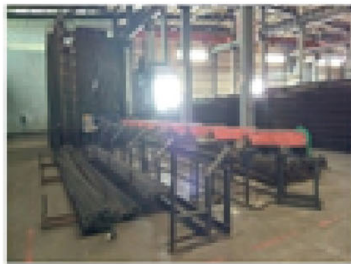

Throwing pill

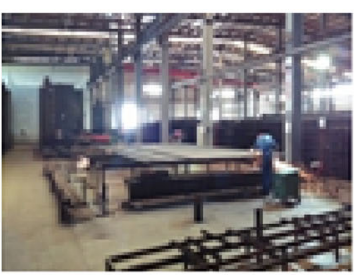

Flaw detection

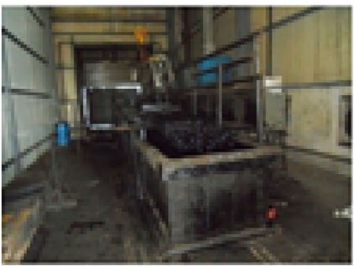

Impregnating varnish

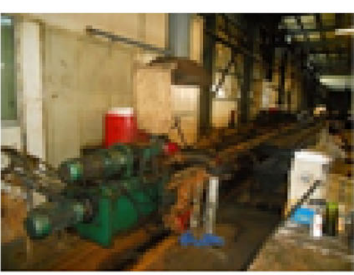

Quenching

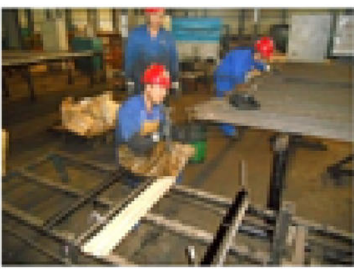

Assembling

Figure 5. Repair technology of waste sucker rods. 
resource and energy consumption, which has outstanding energy saving and emission reduction benefits ( $\mathrm{Xu}$ et al., 2001; Xu, 2007).

Remanufacturing technology is based on waste tubing, and it uses advanced surface engineering technologies with $50 \%$ cost and better performance compared with new one. Meanwhile, remanufacturing technology can achieve production industrialization, and significantly reduce the adverse effects on the environment. At present, various remanufacturing technologies, including nano-composite electro-brush plating technology, coating technology, laser cladding technology, nano-coating technology, etc., have been successfully developed in China, and good results are obtained. Remanufacturing technology for sucker rod is still in its infancy stage, and does not have large-scale application (Hu, Dong, Wang, \& Xu, 2010; Liang, Chen, Bai, Liu, \& Xu, 2010; Liu, Liang, Cheng, Bai, \& Xu, 2008; Song, Li, Deng, \& Hu, 2010; Xu, 2014). The specifications, dimensions and performances of sucker rod and tubing would be changed after remanufacturing, and the existing product standards are no longer applicable. So the new remanufacturing product standards need to be established in order to guide the production and application of remanufacturing sucker rod and tubing.

At present, mature tubing remanufacturing technology is self-propagating high temperature synthesis (SHS) which is using high-temperature synthesis principle to mix $\mathrm{Fe}_{2} \mathrm{O}_{3}$ and $\mathrm{Al}$ powder in proportion with the basic reaction as $2 \mathrm{Al}$ $+\mathrm{Fe}_{2} \mathrm{O}_{3}=\mathrm{Al}_{2} \mathrm{O}_{3}+2 \mathrm{Fe}+836 \mathrm{~kJ} / \mathrm{mol}$. Reaction releases large heat and generates of liquid $\mathrm{Al}_{2} \mathrm{O}_{3}$ and $\mathrm{Fe}$. In centrifugal force, $\mathrm{Al}_{2} \mathrm{O}_{3}$ which has smaller density is distributed in internal surface of steel tube, and Fe which has larger density is distributed between ceramic layer and steel tube to automatically fill the corrosion pits and ditches on internal wall of tubing and integrated with tubing (Figure 6). Eventually ceramic within lining composite steel tube is formed of corundum ceramic layer, ceramic transition layer with iron content gradually increased, iron layer and external steel tube layer from within to outside respectively which achieves waste tubing remanufacturing (Figure 7). The performances of remanufacturing metal-ceramic tubing, including anti-corrosion, anti-abrasion and anti-scaling, is much improved. Combined with port and thread protecting technology, the service life of remanufacturing metal-ceramic tubing is reached more than 3 times compared with normal tubing (Cui, 2000; Ma, Li, Wang, Xu, \& Kang, 2013; Zhang, 1999).

This technology has achieved scale application in Jilin, Changqing, Daqing, Shengli, Yanchang oil fields. For instance of Jilin oil field, 9,505 tons of waste tubing were remanufactured into 7,967 tons of metal ceramic composite tubing via SHS technology. There were no corrosion, abrasion and scaling found during 3 years' application in more than 300 oil and water wells. The service life of remanufactured tubing was over 2 times longer compared with the regular tubing. It reduced 2 times investment on tubing and achieved significant application effects.

If 700,000 tons of waste tubing remanufactured into metal-ceramic tubing annually, it will be reduced by 1.4 million tons of new tubing investments. Remanufactured tubing costs $90 \%$ of regular anti-corrosion tube. The price of regular anti-corrosion tubing is average $85 \mathrm{CNY}$ per meter, so it could save about 650 million CNY by remanufacturing 700,000 tons of waste tubing. And 700,000 tons of manufactured tubing can be used in 50,000 oil or water wells. Due to the manufactured tubing is anti-corrosion, anti-abrasion and anti-scaling, the maintain cycle of water wells can be improved at least $50 \%$. The integrated cost could be deducted by billions. In addition, remanufacturing 700,000 tons of wasted tubing means reducing the production of 2.1 million tons of steel, which can reduce 4.2 million tons of carbon dioxide emissions, save 1.95 million tons of standard coal and 9.45 million tons of water. That's great potential for economic and environmental benefits.
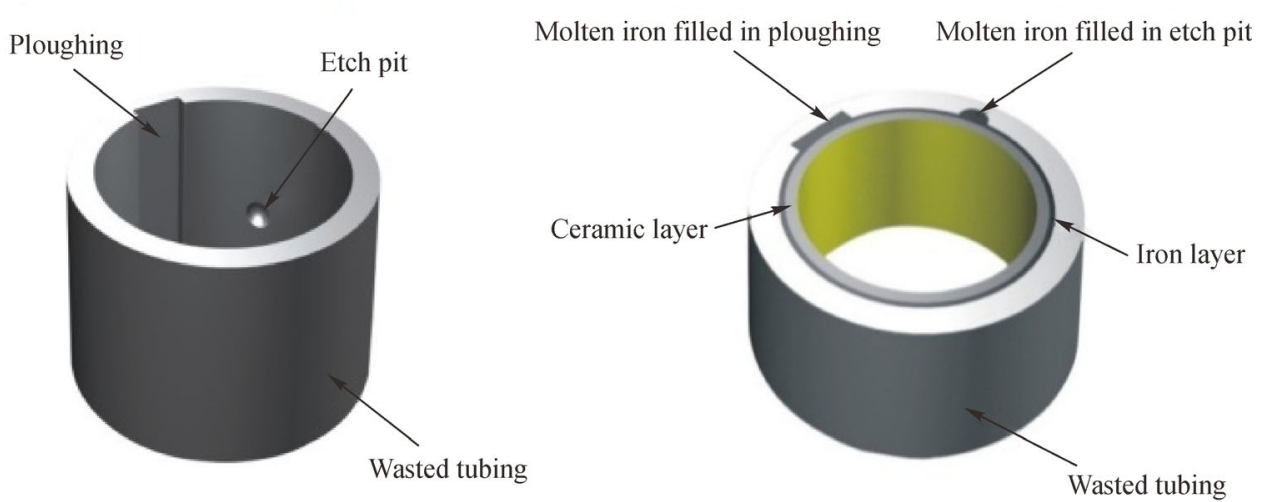

Figure 6. Model of waste tubing remanufacturing. 


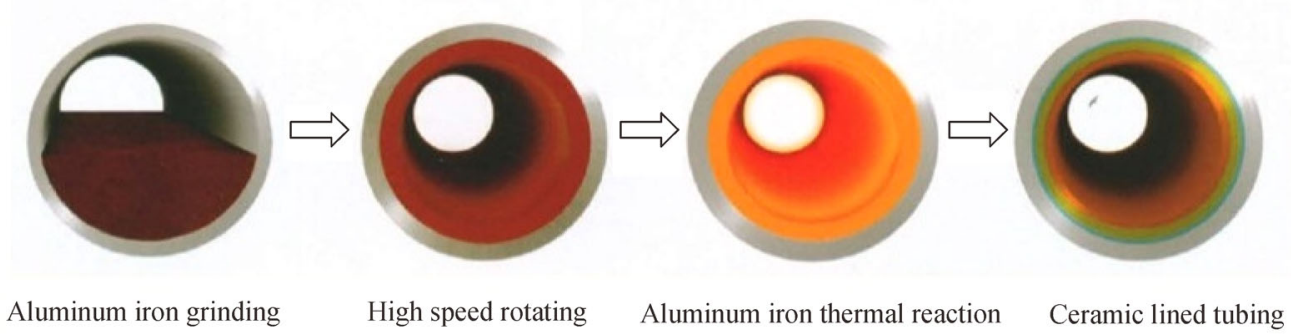

Figure 7. Technological process of SHS.

\section{Suggestions}

During the National Twelfth Five-Year Plan period, China greatly developed "green remanufacturing technology," which has been extremely used in the Field of waste electromechanical products and auto parts, significant economic benefits was achieved. But remanufacturing technology application in the field of petroleum equipment is still in its early stages. With huge application potential, tubing, pump tubing, piston, gear, as the representatives of remanufacturing technology for oil equipment needs very urgent. In response to state policies call for oil industry under the new normal, healthy and stable development of low oil prices, needs to advance the field of advanced manufacturing technology in the petroleum equipment application. The successful experience of remanufacturing technology for combining the existing and future development of remanufacturing technology for oil equipment made the following suggestions.

(1) Develop the research and application of advanced manufacturing technology. Vigorously develop green dismantling and cleaning technology, nondestructive testing and life assessment technology, surface engineering and other remanufacturing key technology, with a focus on remanufacturing of tubing and sucker rod, and gradually expand the scope to components such as gear, plunger, and promoting the application of advanced manufacturing technology in the field of oil equipment.

(2) Promote the standardization and serialization of tubing and sucker rod products. On the basis of the past rejection criterion and remediation technology of tubing and sucker rods, redefining the criterion condition of wasted tubing and sucker rod, the performance evaluation and quality inspection system of manufactured tubing and sucker rod. Establish manufacturing assessment standards and products industry standards concerning the wasted tubing and sucker rods.

(3) Optimize the model of asset management, settle the tubing and sucker rod application management challenges of remanufacturing technology. In the oil business accounting practice, remediation technology is often used as maintenance costs expenditures for enterprise spending. But the quality and technical properties of remanufactured products are meet or exceed new products, the class put on as enterprise technical improvements project, can be charged as capital expenditure. In corporate finance, asset management system of petroleum should be clear for a remanufactured product management, while simplifying management processes, increase efficiency, and scale to promote the creation of conditions for manufacturing technology.

(4) Establish promotion engineering for the enterprises which have advanced manufacturing technology, played a demonstration effect. Based on advanced technology, continuously promote the development of petroleum equipment manufacturing industry in China, establish a social, economic and environmental benefits for one of the petroleum equipment manufacturing industry chain.

\section{References}

Cui, H. (2000). An investigation of ceramic coating formed by selfpropagating high temperature combustion method. China Surface Engineering, 13, 28-30.

Field, J.M., \& Sroufe, R.P. (2007). The use of recycled materials in manufacturing: implications for supply chain management and operations strategy. International Journal of Production Research, 45, 4439-4463.

Hu, G., Wang, S., \& Xu, B. (2000). The engineering of green remanufacture and its application prospect in China. Water Conservancy \& Electric Power Machinery, 23, 33-35.

Hu, Z., Dong, S., Wang, X., \& Xu, B. (2010). New development of nanocomposite electro-brush plating technique facing the equipment remanufacturing. China Surface Engineering, 23, 87-91.

Liang, X., Chen, Y., Bai, J., Liu, Y., \& Xu, B. (2010). An automatic high velocity arc spraying technology applied to remanufacture engine crankshaft. China Surface Engineering, 23, 112-116.

Liu, Y., Liang, X., Cheng, J., Bai, J., \& Xu, B. (2008). Remanufacture of arc spray forming thermal effects. Proceedings of the fourth world con-gress on maintenance, WCM2008, Haikou, China.

Ma, J., Li, G., Wang, H., Xu, B., \& Kang, J. (2013). Research progress on plasma sprayed nanostructured $\mathrm{Al}_{2} \mathrm{O}_{2}-\mathrm{TiO}_{2}$ composite ceramic coatings. Materials Review, 27, 137-141.

Song, J., Li, Y., Deng, Q., \& Hu, D. (2010). Research progress of laser cladding forming technology. Journal of Mechanical Engineering, 
46, 29-39.

Xu, B., Ma, S., Liu, S., Zhu, S., Zhang, W., \& Zhu, S. (2001). Design foundation and key techniques of green remanufacture engineering. China Surface Engineering, 14, 12-15.

$\mathrm{Xu}, \mathrm{B}$. (2007). Equipment remanufacturing engineering theory and technology. Beijing: National Defend Industry Press.
Xu, B. (2010). Remanufacture Engineering and its development in China. China Surface Engineering, 23, 1-6.

$\mathrm{Xu}, \mathrm{B}$. (2014). Green remanufacturing engineering based on ecological civilization construction. Resource Recycling, 11, 17-19.

Zhang, S. (1999). Ceramic-steel composite pipe-the practical application of the SHS coating. China Surface Engineering, 12, 32-36. 